\title{
Operative and nonoperative management of spinal cord injury. A review
}

\author{
W H Donovan MD
}

Professor and Chairman, Department of Physical Medicine and Rehabilitation, University of Texas Health Science Center-Houston; Executive Vice President for Medical Affairs, The Institute for Rehabilitation and Research, Houston, Texas 77030, USA.

Technological developments over the last two centuries have advanced the spinal surgeon's capability to service the needs of the spinal cord injured person. While the role that surgery can play in shortening hospitalization for tetraplegics has yet to be proven, it does play a much needed role in the correction of instability and prevention of deformity when the possibility of these conditions exist. Surgical intervention for purposes of neural decompression has yet to be proven as justifiable in view of the risks involved. All surgical procedures must be undertaken only after due consideration of the patients' general medical condition, including coexisting trauma, the potential for and actual instability and deformity of the spine, and the neurological level and degree of incompleteness of the patient. In general, the greater the remaining neurological function, the more there is to be gained by early mobilization. Yet, in the face of progressive improvement in neurological function, caution is advised since there will be much to lose if anything goes wrong with the operation.

Keywords: spinal cord injury; spine stability; spine deformity; neurological recovery; length of hospitalization; operative management of spinal cord injury; nonoperative management of spinal cord injury.

\section{Historical perspective}

Management of an injury involving the spine and spinal cord has yet to evolve to a point where one set of treatment strategies has been clearly proven to surpass all others. Historically, we know from the Edwin Smith papyrus that from approximately $2500 \mathrm{BC}$ and onwards for the next 4000 plus years it was regarded as an ailment not to be treated. ${ }^{1}$ Disagreements over the effectiveness of the surgeon's contribution to this admittedly difficult to treat malady began to take shape in Great Britain during the early nineteenth century when the nonoperative treatment advocated by $\mathrm{Sir}$ Charles Bell ${ }^{2}$ was challenged by the surgical school led by Sir Astley Cooper. ${ }^{3}$ Cooper and his followers felt that, since at that time death was virtually inevitable in most cases without surgical intervention, there was little to lose by trying to improve matters by an operation. The conservative school, led by Bell, argued that this merely increased the risk of death and threatened any potential spontaneous recovery.

Several extremely important events occurred in the nineteenth and early twentieth centuries that affected the practice of surgery in general and consequently advanced the position that if surgery indeed had something to offer the spinal cord injured (SCI) person, that operation could now be carried out more safely and with less risk of morbidity and mortality. These events occurred in several fields. In the field of microbiology, Louis Pasteur advanced the germ theory of disease and demonstrated sterilization by pasteurization as well as by boiling;, ${ }^{4,5}$ Ignas Semmelweis made some astute observations regarding the transmission of disease by the physician's hands; ${ }^{6}$ Lister promoted the concept of antisepsis and applied it to surgery by using carbolic acid applied to surgical dressings and also used it to cleanse instruments thus affording 
a reasonable expectation of primary wound healing and recovery; ${ }^{7}$ Robert Koch proved beyond a doubt that microbes cause disease and had to be eliminated from the surgical field to assure the prevention of infection; ${ }^{8}$ Halstead introduced the rubber operating glove; ${ }^{9}$ Schimmelbusch introduced steam sterilization; ${ }^{9}$ and Alexander Fleming discovered penicillin which paved the way for the antibiotic era. ${ }^{6,10}$ In the field of anesthesia, important developments included the use of ether by $\mathrm{W} T \mathrm{G}$ Morton and chloroform by John Snow - an achievement first called 'anesthesia' by Oliver Wendel Holmes - and the use of intravenous anesthesia by Ore. Both finally permitted complete freedom from pain during surgery. ${ }^{11}$ In the field of hematology, the discovery of the ABO blood groups by Landsteiner in 1901 unraveled the mystery of transfusion reactions to some degree. Later, Landsteiner and Wiener discovered the Rh system which further reduced the likelihood of incompatibility. When sodium citrate was introduced as an anticoagulant for stored blood in 1914 and when better means for blood collection and storage at blood banks became available after World War II, the safety of spinal surgery was greatly enhanced. ${ }^{12}$

Toward the end of the nineteenth century, Conrad Roentgen discovered the x-ray and this provided the spinal surgeon and all of medical science with a method of imaging internal structures including the spine thereby advancing diagnostic and therapeutic methodologies of spinal disorders. ${ }^{13}$ After World War I, myelography became available, ${ }^{14}$ followed by computer aided tomography (CT) scanning ${ }^{6,15}$ and magnetic resonance imaging (MRI). ${ }^{16,17}$ These three developments were pivotal in allowing all physicians treating trauma and disease of the spine and spinal cord to access the state of the art that we have today for imaging these two structures. CT can detail abnormalities of the bone far better than plain films; MRI can illustrate the soft tissues including the spinal cord, vessels, and discs; while myelography with newer water soluble contrast materials provides valuable information about the neural canal/spinal cord relationships.

Despite all of these advances that have made surgery of the spine and spinal cord far safer, the controversy started by Cooper and Bell continues to this day as to whether it should be done for this group of patients. During the post war era, Sir Ludwig Guttmann $^{18}$ advocated virtually exclusive conservative management and his philosophy gradually spread and held sway throughout much of the world, being accepted, albeit sometimes with modification, by many physicians in Australia, Europe, Asia and Africa. ${ }^{19-22}$ However, even as influential a figure as Guttmann did not go completely unchallenged, even in his own adopted country. ${ }^{23}$ In North America, both the conservative and surgical schools were represented. In 1960 Donald Munro strongly discouraged operative intervention for cervical injuries particularly in the form of surgical fusion. ${ }^{24}$ But there were many others who advocated the contrary, particularly Cloward ${ }^{25-28}$ and impetus for the surgical approach soon gained momentum, particularly in the thoracolumbar and lumbar spine, after Harrington introduced his system of distraction and compression rods and hooks for the treatment of scoliosis. ${ }^{29}$ Many orthopedic surgeons were quick to see the utility of this system for the treatment of other conditions, particularly fracturedislocations of the thoracolumbar spine, ${ }^{18.30}$ particularly since this afforded a far more durable internal fixation than the then existing metal implants, applied to the spinous processes. ${ }^{31}$ Many variations on this theme soon followed including the spring loaded 'dynamic spine alloplasty' which maintained a continuous force in extension to the spine; ${ }^{32}$ the segmental spinal instrumentation, employing posterior rods affixed to the spine by sublaminar wires ${ }^{33}$ and the rods and hooks system of Cotrel and Dubousset with or without pedicle screws. ${ }^{34}$ Pedicle screws as a primary means for maintaining stability of the lumbar spine have recently gained wide acceptance among spine surgeons both in the Americas $^{35-37}$ and in Europe. ${ }^{38-40}$ They offer the advantage of internally immobilizing a short vertebral distance (usually three vertebrae) while still assuring stability.

Thus at this juncture, in the last decade of this century, we find that advances in 
technology have improved the outlook of spinal surgery remarkably. Yet we are still faced with the question when evaluating each injured person, whether it is in that individual's best interest to undergo a surgical procedure. Recently the arguments both pro and con have centered around issues of: cost containment i.e. shorter hospital stays, assurance of stability, correction of deformity and enhancement of neurological recovery. It is worth examining each claim in the light of what experience and the literature has to offer.

\section{Length of hospitalization}

The literature reveals contrary reports on how surgery affects the length of hospitalization in SCI patients particularly as pertains to tetraplegia. Most articles just contain the authors' impressions. Among those that actually measured this parameter, Cotler ${ }^{41}$ and Murphy ${ }^{42}$ report that the length of total hospitalization in a surgically fused group was shorter; Munro ${ }^{24}$ and Tator ${ }^{43}$ report no difference between operated and nonoperated groups. In a recent study by the author, 113 tetraplegic patients (65 managed conservatively and 48 managed surgically) were followed closely for 1 year post injury and even though the operated patients as a whole had a $10 \%$ shorter stay, this did not reach statistical significance. ${ }^{44,45}$

With respect to paraplegics, the issue seems a little clearer. When the lengths of stay of surgically and nonsurgically managed paraplegic patients were compared by Davies, ${ }^{46}$ surgical stabilization was clearly shown to be associated with shorter hospitalizations. This study suffered from the fact that it compared two groups from different spinal cord centers, in different countries, with different health care systems. Yet the difference in total (acute care plus rehabilitation) length of stay was reduced by one third in the operated group. ${ }^{46,{ }^{47}}$ Willen et al also compared paraplegics with thoracolumbar injuries treated conservatively against those who underwent Harrington instrumentation and fusion and in this admittedly small sample, treated in Sweden, found a $25 \%$ reduction in total hospitalization in the operated group compared to a conservatively managed group. ${ }^{48}$ Time to reach maximum 'rehabilitation potential' was also claimed by Jacobs to have been reduced in a group treated with Harrington rods and fusion compared to a group managed conservatively. ${ }^{49}$ Nevertheless, Sumaya et al recently reported a shorter length of stay among a nonoperated group of paraplegics compared to an operated group treated in a rehabilitation hospital in Japan. ${ }^{50}$

Paraplegics in general have fewer pathophysiological changes such as orthostatic hypotension and impaired respiratory function to overcome than do tetraplegics and they have full use of their upper extremities so that they can usually progress through their rehabilitation faster if the period of obligatory bed confinement can be shortened. ${ }^{51}$ Tetraplegic patients, on the other hand, are more autonomically and somatically impaired. More time for adjustments, particularly to cardiovascular and respiratory changes, must be made and special care must be taken to prevent complications, particularly of the respiratory system. In the author's experience, attempts made at shortening the total hospitalization of tetraplegic patients by allowing early mobilization either via surgical intervention or via externally applied orthoses have not been impressive simply because of this obligatory adjustment period and because the need for external bracing impedes the attainment of independence in certain self care and mobility goals even if the patient is allowed out of bed before the typical 6 weeks needed for conservative healing of cervical fractures (Table Ia).

\section{Stability and deformity}

Instability and deformity comprise the biomechanical aspects of spinal cord injury that must concern all who treat this problem. Munro has stated 'the stability of the spine depends on its ligaments and especially on the intervertebral discs and the common spinal ligaments'. ${ }^{52}$ Instability inherently means a condition that allows abnormal movement to occur between adjacent vertebrae. More precise definitions have been offered by White et al who 
Table I Fractures with neurological compromise

\begin{tabular}{|c|c|c|}
\hline Classification & Mechanism & $\mathrm{X}$-ray findings \\
\hline $\begin{array}{l}\text { (a) Cervical } \\
\text { Flexion with } \\
\text { compression }\end{array}$ & $\begin{array}{l}\text { Compression of } \\
\text { anterior aspect of } \\
\text { vertebral body with } \\
\text { longitudinal pull on } \\
\text { posterior ligament } \\
\text { complex with varying } \\
\text { degrees of rupture }\end{array}$ & $\begin{array}{l}\text { Wedge compression } \\
\text { fracture of anterior } \\
\text { body. Separation of } \\
\text { posterior spinous } \\
\text { processes in some } \\
\text { cases } \\
\text { May see retropulsion }\end{array}$ \\
\hline $\begin{array}{l}\text { Flexion with } \\
\text { distraction } \\
\text { (and rotation) }\end{array}$ & $\begin{array}{l}\text { Complete rupture of } \\
\text { posterior ligament } \\
\text { complex. Upper } \\
\text { vertebra may slide } \\
\text { off lower vertebra } \\
\text { producing unilateral } \\
\text { or bilateral 'locked' } \\
\text { facets }\end{array}$ & $\begin{array}{l}\text { Unilateral or } \\
\text { bilateral dislocations } \\
\text { with: } \\
\text { Displacement of } \\
\text { vertebral body } \\
\text { Separation of } \\
\text { spinous processes } \\
\text { Displacement and } \\
\text { locking of articular } \\
\text { processes }\end{array}$ \\
\hline
\end{tabular}

Stability

Comments

Unstable or stable depending on degree of ligament rupture Stable in extension

Stable in extension

\section{Bilateral are} unstable (may be stable in 'locked' position) Unilateral may be stable. Often not associated
with fractures: spontaneous fusion does not occur in $1 / 4$ of patients

Treatment

Conservative

Traction of $6 \mathrm{wks}$, then OOB with

support $\times 6 \mathrm{wks}$ or

halo $\times 12 \mathrm{wks}$

Surgical

ORIF, collar $x$

8-12 wks

Conservative

Reduction:

Skull calipers

Manip under

anesthesia.

Stabilization:

Tongs \& traction $\times$

6 weeks

OOB with collar 6 more wks or halo $\times$

12 weeks.

Surgical

Posterior fusion \&

wiring, then external support for $12 \mathrm{wks}$

Conservative

Tongs \& traction $\times$

6 weeks.

Collar $\times 6$ wks or

halo $\times 12$ weeks

Surgical

ORIF, posterior

and/or anterior-

with plate fixation in

some cases

nucleus of disc is

body which explodes vertebra. May see

retropulsion with neurologica

injury 
Table I (cont)

\begin{tabular}{|c|c|c|c|c|c|}
\hline Classification & Mechanism & X-ray findings & Stability & Comments & Treatment \\
\hline (a) Cervical (cont) & & & & & \\
\hline Extension & $\begin{array}{l}\text { Rupture of anterior } \\
\text { longitudinal ligament } \\
\text { and annulus fibrosus. } \\
\text { Posterior ligaments } \\
\text { unaffected }\end{array}$ & $\begin{array}{l}\text { Tear drop fracture } \\
\text { anteriorly. Separation } \\
\text { of anterior disc space }\end{array}$ & Stable in flexion & $\begin{array}{l}\text { Usually reduces } \\
\text { spontaneously-may } \\
\text { be difficult to } \\
\text { evaluate on x-rays } \\
\text { Often associated } \\
\text { with degenerative } \\
\text { changes }\end{array}$ & $\begin{array}{l}\text { Collar with neck in } \\
\text { flexion } \times 8-12 \mathrm{wks}\end{array}$ \\
\hline
\end{tabular}

\section{(b) Thoracolumbar}

Flexion with

distraction

(and rotation)
Longitudinal and rotational forces across posterior ligament complex with complete rupture Annulus fibrosus resists forces better than vertebral body which shears

\section{Compression}

\author{
Fracture of one or \\ both articular \\ processes. Upper \\ vertebra pulls off top \\ slice of lower \\ vertebra. Separation \\ of spinous processes
}

May appear reduced on x-ray (patient supine and pelvis in line)

\section{Stable}

\section{Expect spontaneous}
Vertebral end plates fractured \& nucleus of disc is forced into vertebral body which explodes

'Burst fixation'

S

\section{Conservative}

Closed reduction

then bed rest $X$

12 wks, then OOB

with jacket $\times 12$ wks

Surgical

ORIF then if

complete $\mathrm{OOB}$

$\mathrm{w} / \mathrm{jacket} \times 12 \mathrm{wks}$, if incomplete, $\mathrm{OOB}$

with jacket $\times 24$

weeks fusion because of

bone disruption
Conservative

Bed rest $\times 4-6$ wks if complete, $\mathrm{OOB}$ with jacket $\times 6 \mathrm{wks}$, if incomplete, 12

weeks

Surgical

ORIF, OOB with

support $\times 12$ weeks

if complete, 24

weeks if incomplete 
proposed measurements of angulation and displacement beyond which failure of the bony and/or ligamentous structures would occur. ${ }^{53} \mathrm{He}$ then defined the term 'clinical instability' to mean 'the loss of the ability of the spine under physiological loads to maintain relationships between vertebrae in such a way that there is neither damage nor subsequent irritation to the spinal cord or nerve roots and, in addition, no development of deformity with excessive pain' ${ }^{54}$ This definition includes the concept of early instability, i.e. unacceptable movement between vertebrae during the acute period that might result in nonunion or mal-union or neural compromise, as well as that of late instability, i.e. progressive changes in alignment that may result in deformity and neurological deterioration. Holdsworth and Denis independently expressed instability in terms of 'theories of columns'. Holdsworth regarded the spine as a two column structure (posterior and anterior) and maintained that failure of the "posterior ligament complex' would allow sufficient abnormal movement to permit nonunion, deformity or further neurological impairment. ${ }^{55}$ Denis represented the spine as a three column structure and, like Holdsworth, classified different types of fractures but explained them on the basis of failure of one or more columns. He was less precise in his definition of instability but considered it in terms of three 'degrees'. ${ }^{56,57}$ Sir George Bedbrook advised that on the basis of his own anatomical dissections if, in the mortuary, one proceeds to transect the ligaments between two adjacent vertebrae in a posterioranterior direction, '(a) the division of the posterior interspinous ligament does not interfere with the stability of the vertebral column, (b) the division of the ligamentum flavum still does not interfere with the immediate stability of the vertebral column, (c) the interarticular facetal joints and their capsule, if disrupted, do not interfere with stability, (d) it is not until the disc is cleanly divided by a sharp knife that the spinal column begins to show some potential instability, (e) it is not until the anterior longitudinal ligament is stripped (but not necessarily divided) that the vertebral column then becomes potentially unstable 
under the influence of stress'. ${ }^{58}$ Whitesides' statement that a stable spine is one that can withstand stress without incurring progressive deformity or further neurological damage is helpful in defining late instability ${ }^{59}$ but still leaves the clinician to make the deduction after viewing all the radiographic and clinical information as to what the potential for abnormal movement may be, based on the information described by the above authors.

It is generally held that a lesion is potentially unstable if it exhibits failure of the posterior and middle columns described by Denis. ${ }^{56}$ Therefore for these lesions, during the acute period post injury, steps must be taken to guard against abnormal movement of the spine. This can be done in most cases by conservative or surgical means but the former must rely much more heavily on a trained, expert nursing staff. $^{19}$ Internal stabilization allows for earlier time out of bed and gives the surgeon some assurance that loss of reduction will not recur during turns in bed, to say nothing of transfers. ${ }^{60}$ However, even fractures that are inherently stable such as burst fractures or those that are purely compression-flexion in type, if managed conservatively will require adequate time for healing before mobilization from bed and will require adequate external support (Table Ia, b). Cheshire reported an incidence of late instability of $7.5 \%$ of all cases treated conservatively. ${ }^{61}$ This was in agreement with Bedbrook who reported an incidence of late instability between 5 and $10 \%$ in a multicenter study. ${ }^{20}$ In the author's recent study of conservatively and surgically managed cervical injuries, at 3 months post injury the nonoperated group had a higher incidence of instability but most of these showed minimal instability (1-5 degrees change of angulation and/or $1-2 \mathrm{~mm}$ change in displacement) on flexion/extension plain radiographs according to criteria modified from White et al. ${ }^{53}$ Yet these all became stable just with maintenance in a soft cervical collar for an additional 3 months. Five other unoperated patients with greater than 5 degrees change in angulation or greater than $2 \mathrm{~mm}$ change in displacement were offered late fusion and two accepted. At 12 months, the difference between the operated and nonoperated groups with respect to instability did not reach significance $(p<0.05)$ even though only the conservative patients were represented at this juncture. Interestingly, all of the patients with either greater than 5 degrees of change of angulation or more than $2 \mathrm{~mm}$ of change in displacement sustained their injuries from a flexion-distraction mechanism where the posterior ligament complex was disrupted. One fourth of the patients with this mechanism of injury became moderately or markedly unstable. ${ }^{45}$ Similarly, in the same study, the surgical group on average had more anatomical restoration and therefore less deformity although the extent of deformity was in all but two cases considered acceptable and of no functional consequence.

Instability and the risk of incurring subsequent deformity is an issue of even greater concern for paraplegics with thoracolumbar or lumbar injuries. The reasons for this include: the greater length of time required for spontaneous fusion that will satisfy White's ${ }^{54}$ criteria for clinical stability (Table $1 \mathrm{~b}$ ); the greater forces acting on the lower parts of the spinal column imposed by gravity and muscular action; the absence of supporting structures, i.e. ribs; and the impairment imposed by the loss of lumbar lordosis when assuming the standing posture. Proponents of conservative treatment of injuries to this region have generally allowed at least 2-3 months of recumbency before permitting sitting or standing activities. ${ }^{19,20,48,62}$ Despite this, the incidence of deformity has been reported to be higher and reduction less often anatomical ${ }^{49,62}$ yet more flexibility is preserved. ${ }^{50}$ Flexion deformity of the lumbar spine is a critical issue for the neurological levels of L1 and below. Standing in knee-ankle-foot orthoses (KAFOs) becomes practical at these levels but only if the lumbar lordosis is preserved. A kyphosis of even 10 degrees can make this difficult since the patient will not be able to place his center of gravity behind the flexion/extension axis of rotation of the hips. ${ }^{63}$ Finally, in this region of the spine, the risk of deformity is increased because the weight bearing load through the damaged vertebrae is greater than it would be through the 
neck (in a cervical injury) and larger and stronger muscles than found in the neck, eg the iliopsoas, quadratus lumborum and muscles originating from the pelvis, can create deforming forces on the fracture when they contract.

From a biomechanical standpoint, it would seem there is a greater need for near anatomical reduction and a need to hold that reduction securely in thoracolumbar and lumbar injuries while at the same time immobilizing as short a number of adjacent vertebrae as possible so that maximum flexibility can be retained. On the other hand, thoracic injuries are usually inherently stable and like cervical injuries can 'tolerate' a somewhat greater deformity without compromising function.

One overriding caveat that should be emphasized is the point that laminectomy following trauma, when performed without an accompanying stabilization procedure for purposes of decompression, does not enhance neurological recovery and exposes the spine to the risks of instability and deformity and even further neurological loss. ${ }^{64-66}$

\section{Neurological recovery}

One further issue bearing on the decision to operate in the acute period is whether any operation can cause, encourage or hasten neurological recovery. This point has been hotly debated on both sides, mostly on the basis of each author's personal experience. ${ }^{19,58,67-71}$ Few studies have been done that actually compare evenly matched groups and none have been done under optimal conditions, i.e. prospective, randomly assigned, controlled studies.

A greater contribution in this area appears to have been made however in the area of pharmacological management. Braken et al have reported that IV administration of methylprednisolone, begun within the first 8 hours post injury, can result in some neurological recovery in both complete and incomplete patients. ${ }^{72}$ Geisler has reported similar salutary effects on a smaller sample using a ganglioside $(\mathrm{GM}-1){ }^{73}$
Young \& Dexter reported slightly greater recovery among patients managed entirely conservatively at Stoke Mandeville Hospital in England compared to a mixed group in Phoenix some of whom were treated operatively and others nonoperatively. ${ }^{74}$ Davies et $a l^{46}$ also compared patients from two different institutions with thoracolumbar injuries but found no difference in the amount of neurological recovery among operated and nonoperated groups. Similarly, no difference in neurological outcome was found by most authors who have studied matched groups in the same institution. ${ }^{42-45.48 .69 .71}$ Bose has taken exception to this however for patients with central cord syndromes, claiming better motor recovery in a group who underwent surgical procedures that were not described. ${ }^{75}$ While most of these studies conclude that operative intervention by experienced surgeons does not aggravate the spinal cord injury, ${ }^{76}$ no procedure thus far devised has been subjected to the rigorous examination similar to that which was done for methylprednisolone and found to be superior to other operative procedures or to none at all.

Although some investigators feel that neural damage is in fact caused by bony damage or dislocation, ${ }^{67}$ it is important to remember that spinal cord injury can occur even in the absence of bony damage, particularly in older age groups, as has been pointed out by Hardy. ${ }^{77}$

Intimately involved in the discussion of neurological improvement is the issue of displacement of bone or disc material into the neural canal producing a traumatic stenosis. There is considerable argument today over whether such stenosis or narrowing of the neural canal, if allowed to persist, does in fact impede recovery. Opinions are divided along similar lines as described above because proponents of surgery often rate 'decompression,' ie restoration of the neural canal, as an important reason for operating in the first place. In some of the studies directed at this issue, where recovery was correlated with the extent of stenosis, no direct correlation could be found by some authors ${ }^{71.78-83}$ while others have stated the opposite. ${ }^{84,85}$ Dall \& Stauffer were able to conclude after a study 
of 14 patients with T12 or L1 burst fractures that while no correlation could be found between neurological recovery and neural canal compromise nor method of management, they did note a more favorable prognosis in those patients with kyphosis less than 15 degrees. ${ }^{79}$

In the author's series, described in part above, no statistically significant difference could be found between comparable groups managed with and without operative fusion with respect to neurological recovery at 3,6 and 12 months post injury and no correlation could be made between the extent of post traumatic stenosis and neurological recovery in either group. ${ }^{45}$

\section{Suggested guidelines regarding operative intervention}

Based on information extant on the subject of early management of SCI, it is recognized that shortening the length of hospitalization, ensuring stability and preventing deformity, and optimizing chances of neural recovery are all desirable things. Some guidelines seem appropriate as to whether these goals should be pursued with or without surgery. At least five factors are involved: (1) the general medical condition, (2) the potential for instability, (3) the degree of deformity present, (4) the degree of incompleteness of the lesion, and (5) the level of the lesion.

\section{General medical condition}

The general medical condition will be the first factor to limit or expand the options available. The victim of polytrauma is more likely to require life saving procedures and support systems that preclude early mobilization.

\section{Instability}

The thoracolumbar junction, the lumbar spine and the midcervical region are the areas at greatest risk of being unstable while the thoracic spine is the most inherently stable section due to the support offered by the rib cage. ${ }^{86}$ The potential for instability can usually be inferred from the $\mathrm{x}$-ray appearance. While instability can in simple terms be regarded as abnormal movement across the injury area, instability is also a relative term. Some lesions may be unstable in the supine position and move abnormally when the patient is turned on to his or her side. Others may be quite stable in the supine position, with or without external support such as tongs and traction, jackets or collars, but may be unstable in the upright position even with a collar or jacket. Most injuries however do not have such complete ligamentous disruption that they are unstable even in the supine position, but it seems logical to consider surgical intervention with internal stabilization in these patients since they will primarily be the ones with severe ligamentous disruption. However, for those that are likely to be unstable only when the body is subjected to the forces of gravity, i.e. when sitting (or standing), surgical intervention need be considered only if sitting is permitted by the medical condition. It seems logical in that instance to perform the surgery well before sufficient time passes for spontaneous adequate bony healing to ensure stability anyway. The time required to ensure such spontaneous healing varies with the location and the mechanism of injury. In general, 6 weeks are required for the cervical region and 8-10 weeks for the lumbar region (Table I). Patients may be allowed out of bed after this time wearing external support. $\mathrm{X}$-rays taken in the upright position while wearing the collar or jacket will disclose whether the force of gravity creates any instability. If so, then further time must be allowed for healing or surgical intervention should be considered. Most cervical injuries will require an additional 6 weeks and lumbar injuries an additional 2-4 months in external support before the injury is healed sufficiently to withstand the forces of full muscle action across the injured area. Xrays taken after the passage of that amount of time, with all support removed in both the flexed and extended positions while sitting, will disclose whether such forces create abnormal movement. If so, then in most cases further healing will not occur and surgical stabilization should be considered. Only a small percentage of the cases managed conservatively will demonstrate this 
'late instability', but those showing a mechanism of flexion with distraction are the most vulnerable. ${ }^{19,45,61}$

\section{Deformity}

The presence of deformity, i.e. angulation or displacement seen on the initial x-rays, will also influence the need for surgery. Alignment does not have to be restored to an anatomical position in order for an acceptable, functional result to be obtained, particularly in the cervical and thoracic spine. However, where angulation exceeds 30 degrees and displacement exceeds one half the width of the vertebral body, a significant deformity will likely result if no attempt is made to reduce the fracturedislocation acutely. This can be done closed or open. Closed reduction is more often employed in injuries to the cervical spine than elsewhere, although it can be used in the lumbar spine as well. ${ }^{63}$ Failure of closed reduction warrants open reduction. The surgical reduction, in turn, must usually be 'held' by some form of metallic device such as wire in the cervical region or metallic devices as described above in the thoracolumbar and lumbar regions. The decision to fuse anteriorly or posteriorly depends upon several factors, but most importantly on the mechanism of injury and whether the majority of the damage is to the anterior or to the posterior elements. Since most ligamentous disruption is caused by flexion injuries, damaging the posterior elements and ligaments, instrumentation and fusion posteriorly is performed more commonly posteriorly and is reported to carry less risk of complications than anterior fusion. ${ }^{87}$

\section{Completeness of lesion}

In general, thoracic lesions are more likely to be complete and lumbar injuries are more likely to be incomplete. Cervical and thoracolumbar lesions occur about equally. ${ }^{86}$ As a rule, the more incomplete the injury, i.e. the lesser the neurological deficit, the more one may justify early mobilization. The mildest cases may require little or no rehabilitation; these patients can be discharged from the acute care hospital directly home providing they are stable and without significant deformity. Therefore if no contraindications exist, a surgical procedure and/or the application of a rigid nonremovable orthosis, e.g. a halo vest, should be considered for very incomplete patients to enhance early mobilization. However when a patient with an incomplete injury is showing progressive neurological recovery, caution must be advised since nothing must be done that might arrest this process. It would be safer to wait until recovery has stabilized. Patients with complete lesions or those with sensory sparing only, particularly tetraplegics and high paraplegics, have the pathophysiological changes mentioned earlier in their respiratory and circulatory systems that will often preclude rapid mobilization, thereby making the case for surgery less compelling. In fact, as long as they receive the necessary expert nursing care and physical and occupational therapy, very little time is lost when the 6 weeks of 'down time' is used to enhance healing, nutrition, and strength in preparation for the added stress imposed by sitting.

\section{Level of lesion}

A better case for early mobilization can be made for lower paraplegics with injuries to the thoracolumbar or lumbar spine. Surgical stabilization can be better justified even in those cases with minimal potential for instability because, as noted above, the cardiovascular and respiratory changes are less problematic, these patients have more residual function, and the weight bearing load across the fracture site demands a longer period of bed rest if treated conservatively. Operative treatment of the fracture can often result in a better anatomical alignment which, as noted above, is more important in those with lumbar injuries since these patients will frequently have sufficient residual function enabling them to walk with braces. In the presence of weak or absent gluteal muscles, the preservation of the normal lumbar lordosis will make ambulation much easier.

Using these five parameters, a rational decision can usually be made about how to proceed with managing the spinal cord 
injured patient. It is important to remember that surgery is not required for bones to heal, nor necessary to reduce or hold a fracture in alignment, since reduction can sometimes be accomplished using closed techniques. However, when the potential for instability seems significant enough, when the likelihood of poor compliance by the patient is a concern, and when a significant deformity will probably result if healing occurs in the position seen on the initial x-rays, then surgery should certainly be considered to correct the problem, providing the patient's general health permits. Surgery is particularly indicated if the degree of incompleteness or the level of lesion permits early mobilization. With these indications Dickson also recommends internal stabilization in special circumstances, i.e. the patient with spinal injuries at multiple levels, the patient requiring surgery on the viscera and the patient with concomitant serious head injuries if their injuries are considered potentially unstable. ${ }^{88}$

None of the above guidelines, it will be noted, deal with the consideration of enhancing neural recovery. In the author's opinion, it has yet to be proven that pursuing this goal in the absence of other indications is worth the risk of the complications and the possible deterioration of neural function from surgery. Although Denis et $a l^{89}$ described how neurological deterioration can occur following conservative management, the possibility of neurological loss following surgical management has been well documented by Marshall et al who describe a $5 \%$ occurrence of neuro- logical deterioration generally among all patients studied and in four of $134(3 \%)$ of the operated patients. ${ }^{90}$ These authors corroborate the work of Heiden et al ${ }^{91}$ who have previously shown that surgery during the first 7 days post injury to the cervical spinal cord carries a significant increase in morbidity and should be avoided. Marshall et al found that of the four patients whose deterioration could be directly linked to an operative procedure, all four had their surgery within the first 5 days post injury. They caution therefore "that early surgical intervention on the cervical spine should be performed under only one circumstance; namely to avoid further deterioration in neurological function'.

This observation does not appear to preclude the performance of surgery for biomechanical considerations at the optimal time since these can usually still be effectively carried out after 1 week. Nevertheless, some still advocate earlier intervention..$^{92}$ In the author's series, ${ }^{45}$ where surgery was performed for biomechanical reasons only, not for purposes of decompression, and no neurological deterioration was noted, the mean time from injury to surgery was 11 days.

\section{Acknowledgement}

This work was supported in part by the United States Department of Education's National Institute on Disability and Rehabilitation Research Spinal Cord Injury Model Demonstrations Grant No. H133N00016.

\section{References}

1 Hughes JT (1988) The Edwin Smith surgical papyrus: An analysis of the first case reports of spinal cord injuries. Paraplegia 26: 71-82.

2 Bell C (1807) A System of Operative Surgery. Longman \& Company, London: 132.

3 Cooper A (1824) A Treatise on Dislocation and on Fractures of the Joints. Longman \& Company. London: 499.

4 Hart M (1978) The 100 Most Influential Persons of History. Hart Publishing Co., New York: 95.

5 Pasteur L (1922) Recherche sur la pétrefaction comtes pednus domadaires. In: Vallery-Rodot P, editor. Oeuvres de Pasteur. Masson et Cie, Paris.

6 Wiltse LL (1991) In: Frymoyer JW, editor. The History of Spinal Disorders in the Adult Spine: Principles and Practice. Raven Press Ltd, New York: 3-16.

7 Lister J (1867) Antiseptic principles in the practice of surgery. BMJ 2: 9-12.

8 Koch R (1912) Die actiolage Dr Mitzbrand-Krankheit Klassker der Medizen. J Barth, Leipzig. 
9 Thurwood J (1957) The Century of the Surgeon. Pantheon Books, New York: 280-289, 296-301.

10 McDermott W, Rogers DE (1982) Social ramifications of control of microbial disease. John Hopkins Med J 151: $301-312$.

11 Kitz RJ, Vandam LD (1986) A history and the scope of anesthetic practice. In: Miller RD, editor. Anesthesia. Vol. 1. Churchill Livingstone, London: 3-12.

12 Wintrobe MM (1962) The Blood Groups and Blood Transfusion in Clinical Hematology. Lea \& Febiger, Philadelphia: 338-375.

13 Roentgen C (1970) In: Talbott J, editor. A Biographical History of Medicine. Grune \& Stratton, Orlando.

14 Sicard JA, Forestiere J (1921) Methode radiographique d'exploration de la cavité epidurale par le lipiodol. Rev Neurol 37: 1264-1266.

15 Houndsfield G (1980) Quoted by Oldendorf WH. The Quest for an Image of the Brain. Raven Press, New York.

16 Moore and Henshaw (1980) Quoted by Oldendorf WH: The Quest for an Image of the Brain. Raven Press, New York.

17 Reid A, Smith FW, Hutchinson JM (1982) Nuclear magnetic resonance and its safety implications: Follow-up of 181 patients. Br J Radiol 55: 784-786.

18 Guttmann L (1976) Management of Spinal Fractions in Spinal Cord Injuries, Comprehensive Management and Research. Blackwell Scientific Publications, Oxford Press: 137-176.

19 Bedbrook GM (1979) Spinal injuries with tetraplegia and paraplegia. J Bone Joint Surg Br 61: 267-284.

20 Bedbrook GM, Edibam RC (1973) The study of traumatic deformity in traumatic spinal paralysis. Paraplegia 10: 321-335.

21 Chahal AS (1975) Results of continuous lumbar traction in acute dorsolumbar spinal injuries with paraplegia. Paraplegia 13: 1-11.

22 Meineke FW (1964) Early treatment of traumatic paraplegia. Paraplegia 3: 262-270.

23 Holdsworth FW, Hardy AG (1953) Early treatment of paraplegia from fractures of the thoracolumbar spine. J Bone Joint Surg Br 35: 540-550.

24 Munro D (1961) Treatment of fractures and dislocations of the cervical spine, complicated by cervical cord and root injuries. New Engl J Med 264: 573-582

25 Cloward RB (1961) Treatment of acute fractures and fractures of the cervical spine by vertebral-body fusion. A report of eleven cases. J Neurosurg 18: 201-209.

26 Bailey RW, Badgley CE (1960) Stabilization of the cervical spine by anterior fusion. J Bone Joint Surg Am 42: $565-594$.

27 Kaplan L, Powell B, Gugnbaum B, Rusk H (1966) Comprehensive Follow Up Study on Spinal Cord Dysfunction. Institute of Rehabilitation Medicine, New York University Medical Center, New York.

28 Rogers WA (1942) Treatment of fractures dislocation of the cervical spine. J Bone Joint Surg Am 24: $245-258$,

29 Harrington PR (1962) Treatment of scoliosis. J Bone Joint Surg Am 44: 591-610.

30 Katznelson AM (1969) Stabilization of the spine in traumatic paraplegia. Paraplegia 7: 33-37.

31 Wilson PD, Straub LR (1952) The Use of a Metal Plate Fastened to the Spinous Processes. American Academy of Orthopedic Surgeons Instructional Course Lectures, Ann Arbor, Michigan.

32 Weiss M (1975) Dynamic spine alloplasty (spring loading devices) after fracture and spinal cord injury. Clin Orthop 112: 150-158.

33 Luque ER, Cassis M, Ramirez-Wiella G (1982) Segmental spinal instrumentation in the treatment of fractures of the thoraco-lumbar spine. Spine 7: 312-317.

34 Cotrel Y, Dubousset J (1985) The use of pedicle screws and universal instrumentation for spinal fixation. Paper presented to the AO Trauma Course, Davos, Switzerland, December 1985.

35 Edwards WC (1985) The sacral fixation device: A new alternative for lumbosacral fixation. Paper presented to the meeting of the North American Spine Society, Laguna Niguel, California, July 1985.

$36 \mathrm{Krag}$ MH, Beynnon BD, Pope MH (1986) An internal fixator for posterior application to short segments of the thoracic, lumbar or lumbosacral spine: Design and testing. Clin Orthop 203: 75-98.

37 Steffee AD, Biscup RS, Sitkowski DJ (1986) Segmental plates with screw fixation. Clin Orthop 203: 45-53.

38 Dick W, Kluger P, Magerl F, Woersdorfer O, Zach G (1985) A new device for internal fixation of thoracolumbar and lumbar spine fractures: The 'Fixateur Interne'. Paraplegia 23: 225-232.

39 Louis R (1986) Fusion of the lumbar and sacral spine by internal fixation with screw plates. Clin Orthop 203: $18-33$.

40 Roy-Camille R, Saillant G, Magel C (1986) Internal fixation of the lumbar spine with pedicle screw plating. Clin Orthop 203: 7-17.

41 Cotler HB, Cotler JM, Alden ME, Sparks G, Biggs CA (1990) The medical and economic impact of closed cervical spine dislocation. Spine 15: 448-453.

42 Murphy KP, Opitz JL, Cabanela ME, Ebersold MJ (1990) Cervical fractures and spinal cord injury. Outcome of surgical and non-surgical management. Mayo Clin Proc 65: 949-959.

43 Tator CH, Duncan EG, Edomon VE et al (1987) Comparison of surgical and conservative management in 208 patients with acute spinal cord injury. Can J Neurol Sci 14: 60-69.

44 Donovan WH, Kopaniky DR, Stolzmann E, Carter RE (1987) The neurological and skeletal outcome in patients with closed cervical spinal cord injury. J Neurosurg 66: 690-694. 
45 Donovan WH, Cifu DX, Schotte DE (1992) Neurologic and skeletal outcomes in 113 patients with closed injuries to the cervical spinal cord. Paraplegia 30: 533-542.

46 Davies WE, Morris JH, Hill V (1980) A analysis of conservative (non-surgical) management of thoracolumbar fractures and fracture dislocations with neural damage. J Bone Joint Surg Am 62: 1324-1328.

47 Dickson JH, Harrington PR, Erwin WD (1978) Results of reduction and stabilization of the severely fractured thoraco and lumbar spine. J Bone Joint Surg Am 60: 799-805.

48 Willen J, Dahllof AG, Nordwall A (1983) Paraplegia in unstable thoraco lumbar injuries: A study of conservative and operative treatment regarding neurological improvement and rehabilitation. Scand $J$ Rehabil Med Suppl 9: 195-205.

49 Jacobs RR, Asher MA, Snider RK (1980) Thoracolumbar spinal injuries. A comparative study of recumbent and operative treatment in 100 patients. Spine 5: 463-477.

50 Suyama T, Tsuyama N, Nihei R et al (1990) Spinal flexibility and activities of daily living for the thoracic and lumbar spinal cord injured-comparison of a non-operated group with an internal spinal fused group. J Japan Orthop Assoc 65: 1155-1164.

51 Donovan WH, Dwyer AP (1984) An update on the early management of traumatic paraplegia (nonoperative and operative management). Clin Orthop 189: 12-21.

52 Munro D (1966) The factors that govern the stability of the spine. Paraplegia 3: 219-228.

53 White AA, Johnson RM, Panjabi MM, Southwick WO (1975) Biomechanical analysis of clinical stability in the cervical spine. Clin Orthop 109: 85-96.

54 White AA, Southwick WO, Panjabi MM (1976) Clinical instability in the lower cervical spine: A review of past and current concepts. Spine 1: 15-27.

55 Holdsworth F (1970) Fractures, dislocations, and fracture-dislocations of the spine. J Bone Joint Surg Am 52: 1534-1551.

56 Denis F (1983) The three column spine and its significance in the classification of acute thoracolumbar spinal injuries. Spine 8: 817-831.

57 Denis F (1984) Spine instability as defined by the three column spine concept in acute spinal trauma. Clin Orthop 189: 65-76.

58 Bedbrook GM (1971) Stability of spinal fractures and fracture dislocations. Paraplegia 9: 23-32.

59 Whitesides TE (1977) Traumatic kyphosis of the thoracolumbar spine. Clin Orthop 128: 78-92.

60 McGuire FA, Neville S, Green BA, Watts C (1987) Spinal instability and the log rolling maneuver. J Trauma 27: 525-531.

61 Cheshire DJE (1969) The stability of the cervical spine following the conservative treatment of fractures and fracture-dislocations. Paraplegia 7: 193-203.

62 Frankel HL, Hancock DO, Hyslop G et al (1969) The value of postural reduction in the initial management of closed injuries of the spine with paraplegia and tetraplegia. Paraplegia 7: 179-192.

63 Donovan WH, Bedbrook GM (1982) Comprehensive management of spinal cord injury. Clinical Symposia. West Caldwell, New Jersey, CIBA Pharmaceutical Division, CIBA Geigy. 34: 2-36.

64 Guttmann L (1969) Spinal deformities in traumatic paraplegics and tetraplegics following surgical procedures. Paraplegia 7: 38-49.

65 Morgan TH, Wharton GW, Austin GW (1971) The results of laminectomy in patients with incomplete spinal cord lesions. Paraplegia 9: 14-23.

66 Roberts JB, Curtiss PH (1970) Stability of the thoracic and lumbar spine in traumatic paraplegia following fracture or fracture dislocation. J Bone Joint Surg Am 52: 1115-1130.

67 Bohlman HH (1979) Acute fractures and dislocations of the cervical spine. J Bone Joint Surg Am 61: $1143-1150$.

68 Ducker TB, Bellegairegue R, Salsman M, Walleck C (1984) Timing of operative care in cervical spinal cord injury. Spine 9: 525-531.

69 Geisler WO, Wynne-Jones M, Jousse AT (1966) Early management of the patient with trauma to the spinal cord. Med Serv J Canada 22: 512-523.

70 Jelsma RD, Rice JF, Jelsma LF, Kusch PT (1982) The demonstration and significance of neural compression after spinal injury. Surg Neurol 18: 79-92.

71 Wagner FC, Chehrazi B (1982) Early decompression and neurologic outcome in acute cervical spinal cord injuries. J Neurosurg 56: 669-705.

72 Bracken MB, Shephard MJ, Collins WH et al (1990) A randomized, controlled trial of methylprednisolone or naloxone in the treatment of acute spinal cord injury: Result of the Second National Acute Spine Cord Injury Study. $N$ Engl J Med 322: 1405-1411.

73 Geisler FH, Dorsay FE, Coleman WP (1991) Recovery of motor function after spinal cord injury-a randomized placebo controlled trial with GM-1 ganglioside. N Engl J Med 324: 1829-1838.

74 Young JS, Dexter WR (1978) Neurologic recovery distal to the zone of injury in 172 cases of closed, traumatic spinal cord injury. Paraplegia 16: 39-49.

75 Bose B, Northrup BE, Osterholm JL et al (1984) Reanalysis of central cervical cord injury management. Neurosurgery 15: $367-372$.

76 Flynn TB (1982) Neurologic complications of anterior cervical interbody fusion. Spine 7: 536-539.

77 Hardy AG (1977) Cervical spinal cord injury without bony injury. Paraplegia 14: 296-305.

78 Beatson TR (1963) Fractures and dislocation of the cervical spine. J Bone Joint Surg Br 45: 21-35. 
79 Dall BE, Stauffer ES (1988) Neurologic injury and recovery patterns in burst fractures at the T12 or L1 motion segment. Clin Orthop 233: 171-176.

80 Doll DM (1972) Injuries of the cervical spine: I. Does the type of bony injury affect spinal cord recovery? $S$ A Med J 46: 1048-1050.

81 Horlyck E, Rahbek M (1972) Cervical spine injuries. Acta Orthop Scand 45: 845-852.

82 Iiguka IK (1972) Correlation of neurologic and recent genologic findings in fracture dislocation of cervical vertebrae. Vopr Neiokhir 36: 46-48 (Russian).

83 Herndon WA, Galloway D (1988) Neurological return versus cross sectional canal area in incomplete thoracolumbar spinal cord injuries. J Trauma 28: 680-683.

84 Braakman R, Vinken PF (1967) Unilateral facet interlocking in the lower cervical spine. J Bone Joint Surg Br 49: 249-257.

85 Brau EA, Miller JA, Bougard WC (1963) Traumatic dislocation of the cervical spine: Army experience and results. J Trauma 3: 569-582.

86 Meyer PR, Cotler HB (1990) In: Meyer PR, Cotler JM, Cotler NB, editors. Fusion Techniques for Traumatic Injuries in Spinal Fusion: Science and Techniques. Springer Verlag, New York: 189-246.

87 Capen DA, Garland DE, Waters RL (1991) Surgical stabilization of the cervical spine. A comparative analysis of anterior and posterior fusion. Clin Orthop 166: 229-237.

88 Dickson RA (1991) Spinal injuries: Early surgical treatment. Paraplegia 30: 43-45.

89 Denis F, Armstrong GWD, Searle K, Matte L (1984) Acute thoracolumbar burst fracture in the absence of neurologic deficit. A comparison between operative and nonoperative treatment. Clin Orthop 189: 142-149.

90 Marshall LF, Knowlton S, Garfin SR et al (1987) Deterioration following spinal cord injury. A multicenter study. J Neurosurg 66: 400-404.

91 Heiden JS, Weiss MH, Rosenberg AW et al (1975) Management of cervical spinal cord trauma in Southern California. J Neurosurg 43: 732-736.

92 Gertzbein SD, Crowe PJ, Fazl M et al (1992) Canal clearance in burst fractures using the AO internal fixator. Spine: 558-560. 